\title{
Analysis of the variation pattern in left upper division veins and establishment of simplified vein models for anatomical segmentectomy
}

\author{
Min Zhang ${ }^{1 \#}$, Ning Mao ${ }^{2 \#}$, Ke Zhang, ${ }^{3,4,5 \#}$, Miao Zhang ${ }^{6}$, Yun Liu ${ }^{7}$, Ren-Feng Wang ${ }^{8}$, Tao Xiong ${ }^{2}$, \\ Gang Huang', Jian-Fei Shen ${ }^{10}$, Jun Liu ${ }^{11}$, Qing-Chen Wu ${ }^{1}$, Ming-Jian Ge ${ }^{1}$
}

${ }^{1}$ Department of Cardiothoracic Surgery, the First Affiliated Hospital of Chongqing Medical University, Chongqing, China; ${ }^{2}$ Department of Cardiothoracic Surgery, Yongchuan Hospital of Chongqing Medical University, Chongqing, China; ${ }^{3}$ Department of Thoracic Surgery, Affiliated Hospital of Hebei University, Hebei, China; ${ }^{4}$ Basic Research Key Laboratory of General Surgery for Digital Medicine, Shijiazhuang, China; ${ }^{5}$ Institute of Life Science and Green Development, Hebei University, Shijiazhuang, China; ${ }^{6}$ Department of Thoracic Surgery, Xuzhou Central Hospital Affiliated to Southeast University, Xuzhou, China; ${ }^{7}$ Department of Cardiothoracic Surgery, The First College of Clinical Medical Science, China Three Gorges University, Yichang, China; ${ }^{8}$ Department of Thoracic Surgery, Xiamen Branch, Zhongshan Hospital, Fudan University, Xiamen, China; ${ }^{9}$ Department of Thoracic Surgery, the 3rd Hospital of Hebei Medical University, Shijiazhuang, China; ${ }^{10}$ Department of Cardiothoracic Surgery, Taizhou Hospital of Zhejiang Province affiliated to Wenzhou Medical University, Linhai, China; ${ }^{11}$ Department of Thoracic Surgery, First People's Hospital of Yunnan Province, Kunming University of Science and Technology, Kunming, China

Contributions: (I) Conception and design: M Zhang; (II) Administrative support: N Mao; (III) Provision of study materials or patients: K Zhang; (IV) Collection and assembly of data: QC Wu; (V) Data analysis and interpretation: MJ Ge; (VI) Manuscript writing: All authors; (VII) Final approval of manuscript: All authors.

"These authors contributed equally to this work.

Correspondence to: Ming-Jian Ge. Department of Cardiothoracic Surgery, the First Affiliated Hospital of Chongqing Medical University, Chongqing 400016, China. Email: doctor1984@sina.com.

Background: Three-dimensional computed tomography bronchography and angiography (3D-CTBA) is a powerful tool to analyze pulmonary anatomy. We used 3D-CTBA to analyze variations of the pulmonary veins of the left upper division (LUD) and created a simplified LUD vein model.

Methods: Between January 2019 and October 2019, 124 patients with left-sided pulmonary lesions were admitted and underwent 3D-CTBA prior to surgery. We reviewed the anatomical variations of the LUD veins in these patients using 3D-CTBA images and classified them according to their position in relation to the bronchus. To facilitate this process, the same nomenclature as that used to describe the veins of the right upper lobe (RUL) is used for the LUD.

Results: The pattern of LUD veins could be classified into three forms: an anterior + central form, an anterior form and a central form. For the central form, $\mathrm{V}^{1+2} \mathrm{a}, \mathrm{V}^{1+2} \mathrm{~b}, \mathrm{~V}^{1+2} \mathrm{c}$ and $\mathrm{V}^{1+2} \mathrm{~d}$ drained into $\mathrm{V}$. cent. For the anterior form, $\mathrm{V}^{1+2} \mathrm{~d}$ drained into $\mathrm{V}$. ant. The anterior + central form could be further classified into three subtypes ( $\mathrm{V}$ abc, $\mathrm{V}$ ab and $\mathrm{V}$ a).

Conclusions: This is the first report to categorize the pattern of veins in the LUD. This may facilitate the creation of simplified models for use in pre-operative planning for segmentectomy.

Keywords: Vein; left upper division (LUD); ascending $\mathrm{A}^{3}$ a (ASC. $\mathrm{A}^{3} \mathrm{a}$ ); early-bifurcation $\mathrm{B}^{3}$ a; three-dimensional computed tomography bronchography and angiography (3D-CTBA)

Submitted Sep 23, 2020. Accepted for publication Nov 11, 2020.

doi: $10.21037 /$ atm-20-6925

View this article at: http://dx.doi.org/10.21037/atm-20-6925 


\section{Introduction}

The increased use of high-resolution computed tomography (HRCT) has resulted in the detection of an increasing number of patients with ground glass opacity (GGOs) (1). GGOs of less than $2 \mathrm{~cm}$ in diameter and a consolidation tumor ratio of less than $50 \%$ are best treated with segmentectomy in comparison to lobectomy, as this results in less sacrifice of lung volume and more protection of lung function (1). However, because of the anatomical complexity and variations involved, segmentectomy is technically more difficult than lobectomy. It is therefore highly desirable for thoracic surgeons to know the precise anatomy of their patients before surgery.

In comparison to conventional CT images, threedimensional computed tomography bronchography and angiography (3D-CTBA) imaging is a powerful tool allowing thoracic surgeons to determine pulmonary anatomy both before and during surgical procedures. Segmentectomies are most frequently performed upon the right upper lobe (RUL) and several studies have investigated its bronchovascular variations and nomenclatures $(2,3)$. In these, the branching of the right upper pulmonary vein was defined as anterior vein (V. ant) and central vein (V. cent). The branching pattern was classified into three types: anterior + central vein type, anterior vein type and central vein type (2). We have previously reported an assessment of pulmonary vasculature in the bifurcated RUL (3). There are few studies, however, detailing anatomical variations in the left lung, resulting in a nomenclature which is not uniform. This report focusses on the nomenclature and variation of veins in the LUD, which were clearly demonstrated with 3D-CTBA. We present this article in accordance with the MDAR reporting checklist (available at http://dx.doi. org/10.21037/atm-20-6925).

\section{Methods}

\section{Patient characters and Reconstruction of $3 D-C T B A$}

Between January 2019 and October 2019, a total of 124 patients with left pulmonary lesions were included in the study. All patients underwent 3D-reconstruction before surgery. CTPA and CTPV by SOMATOM Definition Flash dual-source computed tomography were performed for each patient. Radiology colleagues processed all 3D images, and thoracic surgeons confirmed the validity of all reconstructions. The study was conducted in accordance with the Declaration of Helsinki (as revised in 2013) and approved by the Ethics Committee of our hospital (No. 2020-206). The informed consent was obtained from each patient.

\section{Nomenclature and variation in bronchovascular pattern}

The segmental and subsegmental pulmonary arteries parallel the bronchi and are named according to the bronchopulmonary segments they supply. The pulmonary vein branches run within interlobular septa and do not parallel the segmental or sub segmental pulmonary artery branches and bronchi. There is considerable variation in the nomenclature of these structures. The classical branching of the RUL vein is as follows: (I) the anterior vein (V. ant) which originates from the $\mathrm{V} 1 \mathrm{~b}$, and drains into the main RUL vein from the mediastinal side; (II) central vein (V. cent), which originates from the $\mathrm{V} 2 \mathrm{a}$, descends through the center of the upper lobe then drains into the main RUL vein.

The left upper lobe, is usually comprised of four vein branches: $\mathrm{V}^{1+2}$ (V.apicodorsalis), $\mathrm{V}^{3}$ (V.ventralis), $\mathrm{V}^{4}$ (V.lingualis superior) and $\mathrm{V}^{5}$ (V.lingualis inferior). $\mathrm{V}^{1+2}$ has four branches as follows: $V^{1+2}$ a (between $S^{1+2}$ a and $S^{3} c$ ), $\mathrm{V}^{1+2} \mathrm{~b}$ (between $\mathrm{S}^{1+2}$ a and $\mathrm{S}^{1+2} \mathrm{~b}$ ), $\mathrm{V}^{1+2} \mathrm{c}$ (between $\mathrm{S}^{1+2}$ $\mathrm{b}$ and $\mathrm{S}^{1+2} \mathrm{c}$ ) and $\mathrm{V}^{1+2} \mathrm{~d}$ (between $\mathrm{S}^{1+2} \mathrm{c}$ and $\mathrm{S}^{3} \mathrm{a}$ ). $\mathrm{V}^{1+2} \mathrm{a}$, $\mathrm{V}^{1+2} \mathrm{~b}$ and $\mathrm{V}^{1+2} \mathrm{c}$ always form a common trunk branching $\left(\mathrm{V}^{1+2} \mathrm{a}-\mathrm{c}\right)$ passing between $\mathrm{B}^{1+2}$ and $\mathrm{B}^{3}$, which then drains into the main LUL vein from the mediastinal side. $\mathrm{V}^{1+2} \mathrm{~d}$ usually joins caudally with $\mathrm{V}^{3} \mathrm{a}+\mathrm{b}$, forming a common trunk passing between the upper division bronchus $\left(\mathrm{B}^{1-3}\right)$ and lingular division bronchus $\left(\mathrm{B}^{4+5}\right.$ ) (Figure 1 ). In some cases, $\mathrm{V}^{1+2} \mathrm{~d}$ drains more cephalically into the $\mathrm{V}^{1+2} \mathrm{a}-\mathrm{c}$, forming a larger common trunk of $\mathrm{V}^{1+2}$ a-d (Figure 2).

The LUL is supplied by three arteries in $22.7 \%$ of patients, 4 arteries in 50\%, 5 arteries in $22.7 \%$, and 6 arteries in $4.5 \%$ (4). We noted an ascending $\mathrm{A}^{3}$ a (ASC. $\left.\mathrm{A}^{3} \mathrm{a}\right)$, arising from the interlobar pulmonary artery, proximal to $\mathrm{A}^{4}$ a and distal to $\mathrm{A}^{1+2} \mathrm{c}(5)$ (Figures 3,4$)$.

$\mathrm{B}^{3}$ is mostly composed of $\mathrm{B}^{3} \mathrm{a}$ and $\mathrm{B}^{3} \mathrm{~b}+\mathrm{c}$ in approximately $90 \%$ of patients (5). The arising point of $\mathrm{B}^{3}$ a varies among patients. We define the arising point of $\mathrm{B}^{3} \mathrm{a}$ as " $\mathrm{a}$ ", the arising point of $\mathrm{B}^{1+2} \mathrm{c}$ as "c", and the bifurcated point of $\mathrm{B}^{1+2}$ and $\mathrm{B}^{3}$ as " $\mathrm{b}$ ". The distance between " $\mathrm{a}$ " and "b" was " $X$ ", and the distance between "b" and "c" was "Y". The " $f$ " is X/Y (Figure 5).

\section{Statistics}

All statistical analyses were performed with GraphPad 


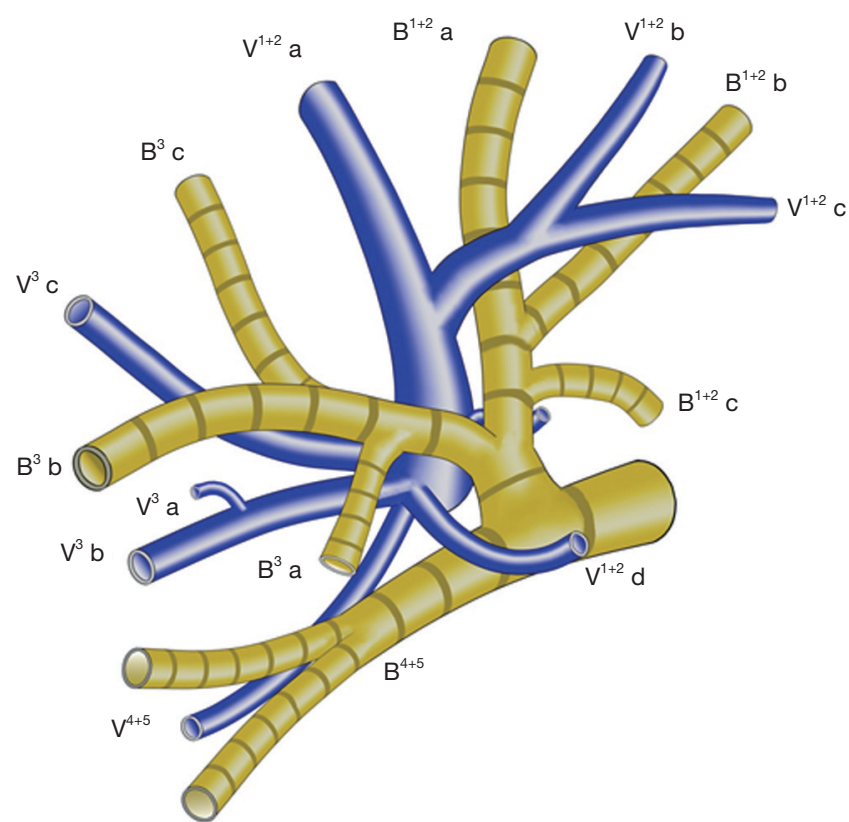

Figure 1 The pattern of vein drainage in left upper division: $\mathrm{V}^{1+2} \mathrm{~d}$ joins caudally with $\mathrm{V}^{3} \mathrm{a}+\mathrm{b}$.

Prism 5.0 (CA, USA) and SPSS 23.0 (SPSS, Chicago, Illinois, USA). Continuous variables are reported as mean \pm standard deviation (SD) or as medians (interquartile range, IQR). Categorical variables are expressed as numbers (percentages). Comparison between groups were assessed by using Student's $t$ test or one-way ANOVA for parametric data, Mann-Whitney U test for nonparametric data, and Pearson Chi-Square test for categorical data. A value of $\mathrm{P}<0.05$ (two-sided) was considered statistically significant.

\section{Results}

The mean age of the 124 patients ( 83 females and 41 males) was 54 years. We define the branching of the veins in the LUD as follows: (I) the anterior vein (V. ant) which originates from $\mathrm{V}^{1+2} \mathrm{a}$, merges with or without $\mathrm{V}^{1+2} \mathrm{~b}$ and $\mathrm{V}^{1+2} \mathrm{c}$, descends anteriorly to $\mathrm{B} 3$, and drains into the main LUL vein from the mediastinal side, and (II) the central vein $\left(V\right.$. cent), which originates from $V^{1+2} d$, descends between $\mathrm{B}^{3}$ and $\mathrm{B}^{4+5}$, merges with $\mathrm{V}^{3} \mathrm{a}+\mathrm{b}$ and drains into the main LUL vein through the center of the upper lobe. Patterns of the LUD vein drainage were classified into three forms (Figure 6). The central form, in which $\mathrm{V}^{1+2} \mathrm{a}-\mathrm{c}$ drains into $\mathrm{V}^{1+2} \mathrm{~d}$ to form the common trunk of $\mathrm{V}$. cent, was seen in 4 cases (3\%). The anterior form, in which $\mathrm{V}^{1+2} \mathrm{~d}$ drains

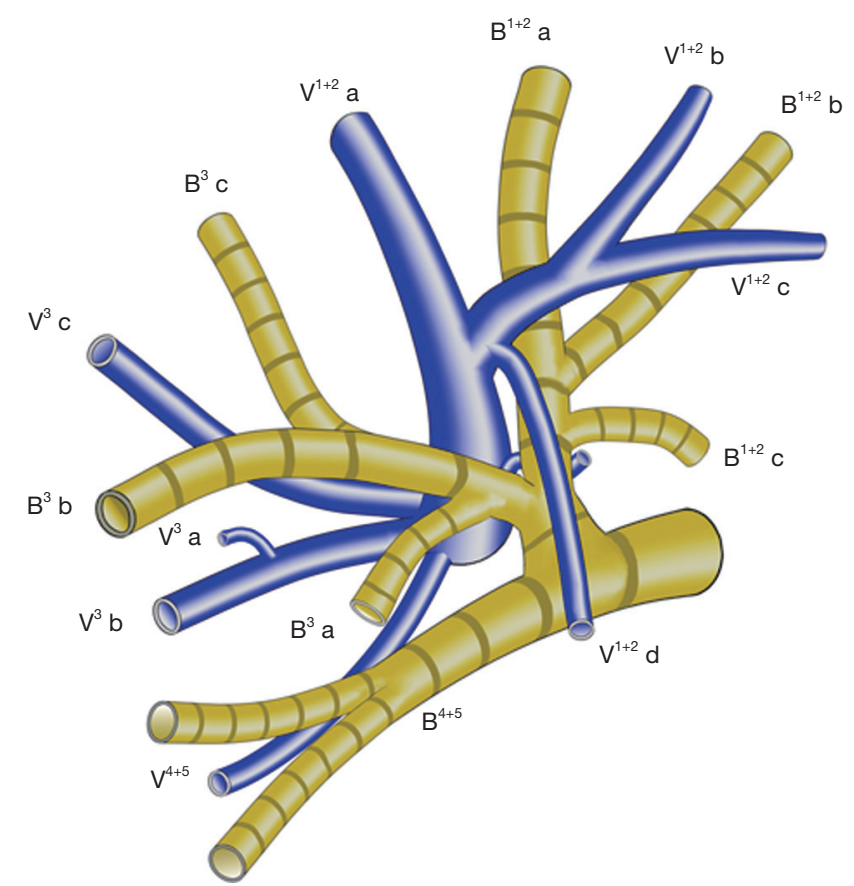

Figure 2 The pattern of vein drainage in left upper division: $\mathrm{V}^{1+2} \mathrm{~d}$ joins into the $\mathrm{V}^{1+2} \mathrm{a}$-c.

into V. ant was seen in 27 cases (22\%). The anterior+central form, which was evident in 93 cases $(75 \%)$, was further classified into three types (Vabc, Vab and Va) (Figure 6). In the Vabc type, $\mathrm{V}$. ant, which originates from $\mathrm{V}^{1+2} \mathrm{a}$ and merges with $\mathrm{V}^{1+2} \mathrm{~b}$ and $\mathrm{V}^{1+2} \mathrm{c}$, was present in 60 cases (48\%). In the Vab type, $\mathrm{V}$. ant originates from $\mathrm{V}^{1+2} \mathrm{a}$ and merges with $\mathrm{V}^{1+2} \mathrm{~b}$, whereas $\mathrm{V}^{1+2} \mathrm{c}$ drains into $\mathrm{V}$. cent. This was seen in 10 cases (8\%). In the Va type, $\mathrm{V}$. ant originates only from $\mathrm{V}^{1+2} \mathrm{a}$, whereas $\mathrm{V}^{1+2} \mathrm{~b}$ and $\mathrm{V}^{1+2} \mathrm{c}$ drain into $\mathrm{V}$. cent. This was seen in 23 cases (19\%).

As detailed in Table S1, the incidence of ASC. A ${ }^{3}$ a was $56.3 \%(18 / 32)$ in the anterior form (group 1) and $2.2 \%$ (2/92) in others forms (group 2) $(\mathrm{P}<0.001)$. This indicates that ASC. $\mathrm{A}^{3} \mathrm{a}$ is most common in the anterior form. The $f(\mathrm{X} / \mathrm{Y})$ was used to reflect the early bifurcation of $\mathrm{B}^{3}$ a (Figure 5). The $f$ was $0.560(0.454-0.846)$ in group 1 and $1.458(0.999-2.259)$ in group $2(\mathrm{P}<0.001)$ (Figure 7), which indicates that the early bifurcation of $\mathrm{B}^{3} \mathrm{a}$ is also usually coexistent with the anterior form.

\section{Discussion}

The pattern of vein drainage in the RUL is well researched and reported $(2,3)$. However, the pattern of venous 


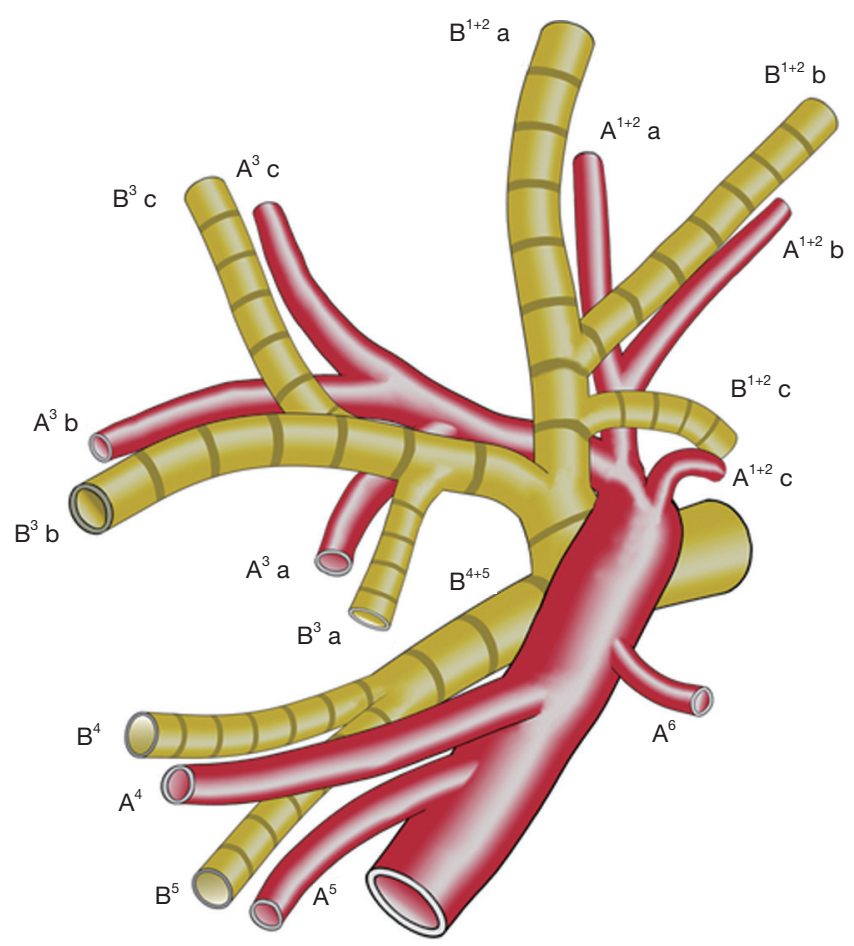

Figure 3 The pattern of artery in left upper lobe without ascending $\mathrm{A}^{3}$ a (ASC. $\mathrm{A}^{3}$ a) and early-bifurcation of $\mathrm{B}^{3}$ a.

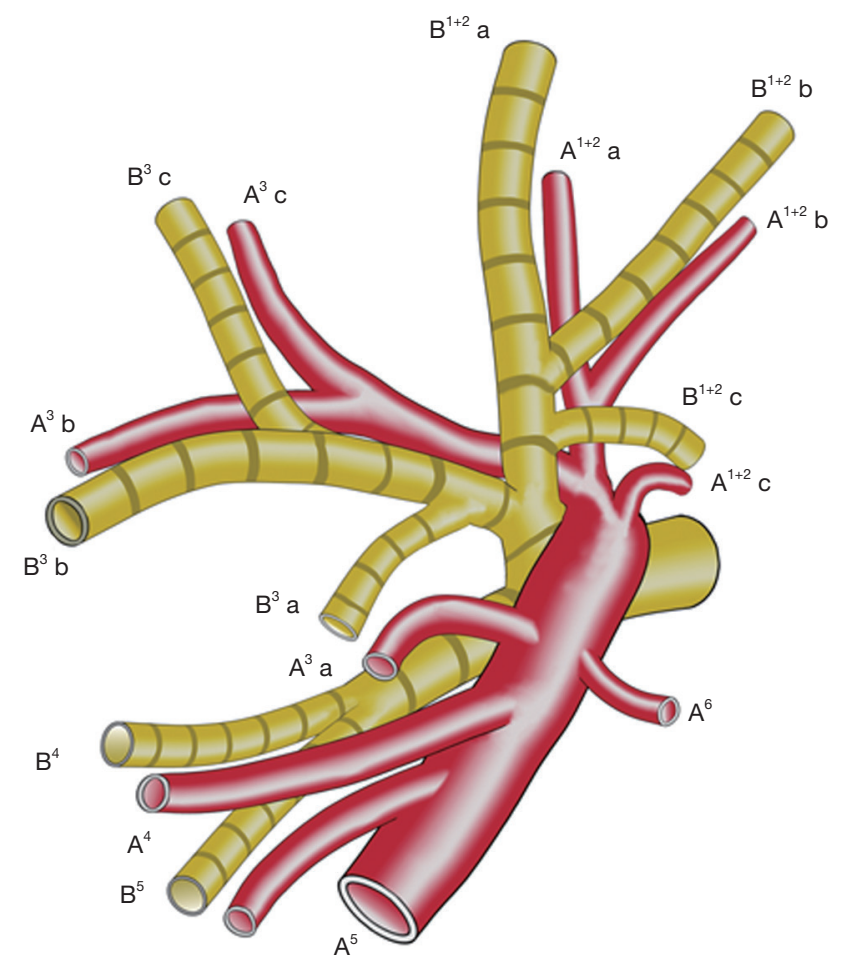

Figure 4 The pattern of artery in left upper lobe with ascending $\mathrm{A}^{3}$ a (ASC. $\mathrm{A}^{3}$ a) and early-bifurcation of $\mathrm{B}^{3}$ a.

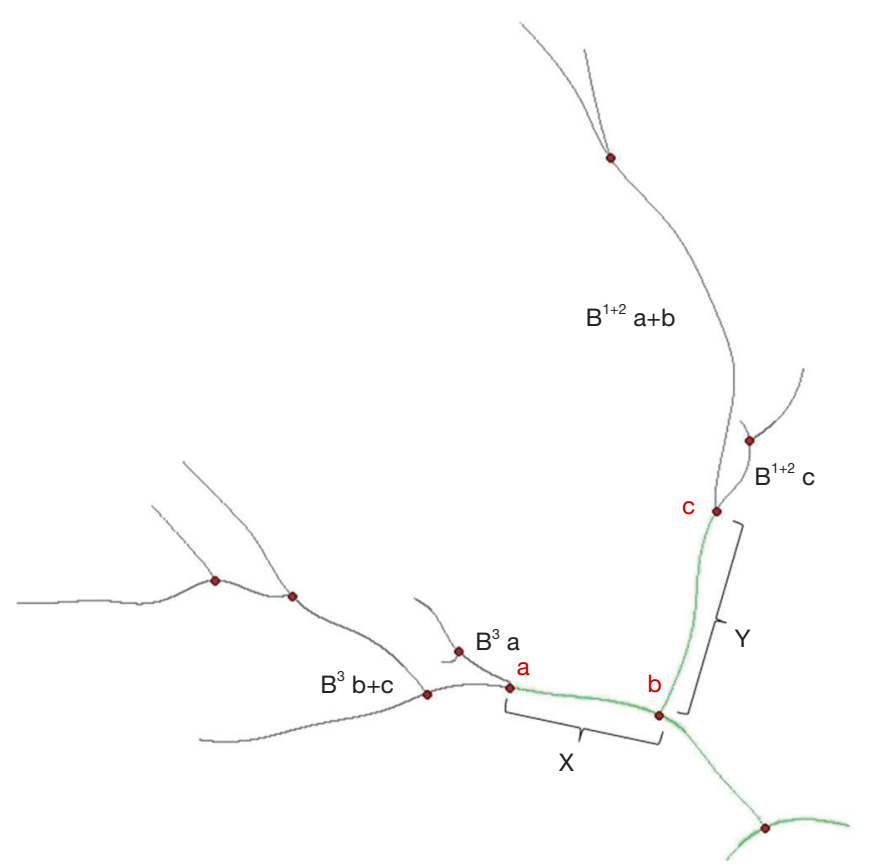

Figure 5 Airway centerline and bifurcation points of airway model in left upper division.

drainage in the LUD is rarely reported. There may be several reasons for this. Firstly, the RUL attracts a high level of attention and investigation because of its relatively higher incidence of tumor resulting in a greater number of lobectomies and segmentectomies. Secondly, the location and identification of the pulmonary artery is relatively easy because it always follows the bronchus. The segmental and subsegmental pulmonary arteries which parallel the bronchi are named according to the pulmonary segments they supply. The segmental and subsegmental pulmonary vein branches, however, run within interlobular septa and do not parallel the segmental or subsegmental pulmonary artery branches and bronchi. Traditional invasive radiological catheterization methods seldom reach the level of the pulmonary segment, let alone the level of subsegment (6). The location and identification of venous structures is therefore both more complex and difficult to visualize. The third reason which contributes to a lack of knowledge of venous anatomy of the LUD relates to the increased use of lobectomy; a procedure which does not rely on detailed knowledge of the pulmonary segment or subsegment veins.

Recent advances in computed tomography and volumerendering reconstruction techniques have facilitated the reconstruction of $3 \mathrm{D}$ images in a non-invasive manner. A powerful tool for thoracic surgeons to determine 

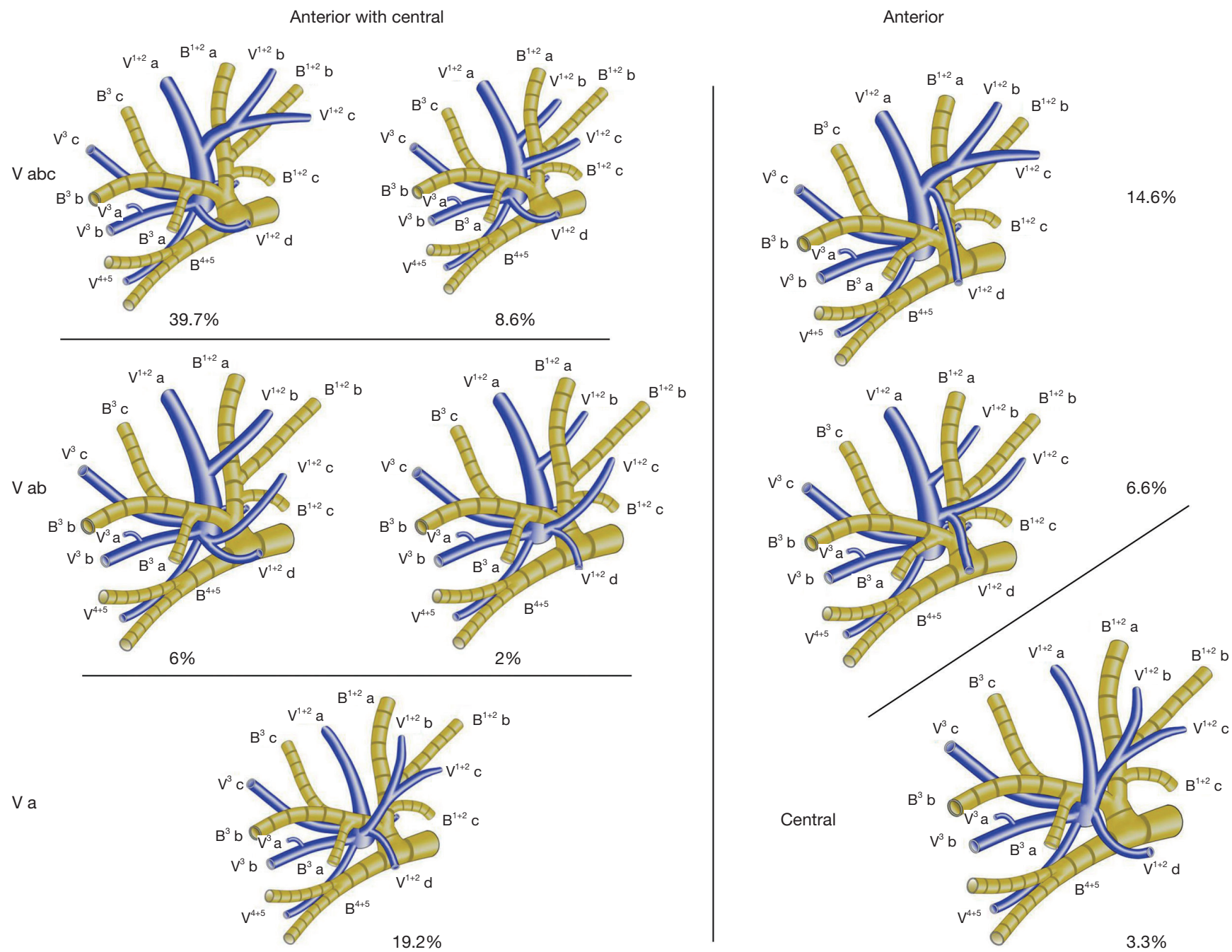

Figure 6 Patterns of branching of veins in left upper division and simplified models.

pulmonary anatomy, including bronchovascular anatomy at the segment/subsegment level, 3D CTBA provides a better understanding of the pulmonary anatomy in patients before and during surgical procedures, including bronchovascular anatomy at the segment/subsegment level. In this article, for the first time in literature, we proposed the same nomenclature of LUD vein with that of the RUL.

A further interesting finding of this study concerns ASC. $\mathrm{A}^{3} \mathrm{a}$. The incidence of ASC. $\mathrm{A}^{3} \mathrm{a}$ in the general population is estimated to be $10 \%$ (5) This incidence is, however, significantly higher $(56.3 \%)$ in the anterior form $(\mathrm{P}<0.001)$. Coincidently, $\mathrm{B}^{3}$ a arises significantly earlier in the anterior form $(\mathrm{P}<0.001)$. This can be explained by the paralleling relationship between segmental/subsegmental arteries and the bronchi. Anatomically, $\mathrm{V}^{1+2} \mathrm{~d}$ locates between $\mathrm{S}^{1+2} \mathrm{c}$ and $\mathrm{S}^{3}$ a as an intersegmental vein. In the anterior form, $\mathrm{V}^{1+2} \mathrm{~d}$ drains more cephalically into $\mathrm{V}^{1+2}$ a-c, forming a larger common trunk of $\mathrm{V}^{1+2} \mathrm{a}$-d. This slight shift of the intersegmental vein results in an elevated intersegmental plane between $\mathrm{S}^{1+2}$ and $\mathrm{S}^{3}$. To adopt to the elevated intersegmental plane, $\mathrm{A}^{3} \mathrm{a}$ arises more frequently from the interlobar artery as ASC. $\mathrm{A}^{3} \mathrm{a}$, and $\mathrm{B}^{3}$ a arises earlier from the bifurcation point. We define the coexistence of ASC. $\mathrm{A}^{3} \mathrm{a}, \mathrm{V}^{1+2}$ a-d and early-bifurcation of $\mathrm{B}^{3}$ a as "Chongqing's triad".

\section{Conclusions}

This is the first report to categorize the intersegmental pulmonary venous patterns of the upper division of the LUL, and to create simplified models for use when 


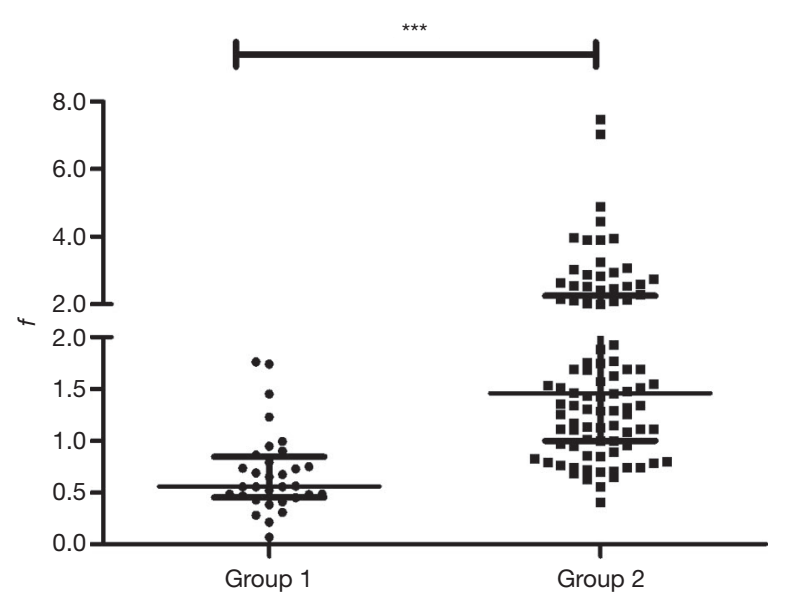

Figure 7 The $f$ was $0.560(0.454-0.846)$ in group 1 and 1.458 (0.999-2.259) in group $2\left({ }^{* * *} \mathrm{P}<0.001\right)$.

planning anatomical segmentectomy. To facilitate this, we used the same nomenclature as that used for the RUL. This knowledge will assist in the preoperative planning of LUD segmentectomy.

\section{Acknowledgments}

Funding: This work was supported by the Research and development of $3 \mathrm{D}$ printing lung cancer surgery planning model including real segmental boundary and complete tissue structure, Key Research and Development Project of Hebei Province, China (19277731d).

\section{Footnote}

Reporting Checklist: The authors have completed the MDAR reporting checklist. Available at http://dx.doi.org/10.21037/ atm-20-6925

Data Sharing Statement: Available at http://dx.doi. org/10.21037/atm-20-6925

Conflicts of Interest: All authors have completed the ICMJE uniform disclosure form (available at http://dx.doi. org/10.21037/atm-20-6925). The authors have no conflicts of interest to declare.

Ethical Statement: The authors are accountable for all aspects of the work in ensuring that questions related to the accuracy or integrity of any part of the work are appropriately investigated and resolved. The study was conducted in accordance with the Declaration of Helsinki (as revised in 2013) and approved by the Ethics Committee of our hospital (No. 2020-206). The informed consent was obtained from each patient.

Open Access Statement: This is an Open Access article distributed in accordance with the Creative Commons Attribution-NonCommercial-NoDerivs 4.0 International License (CC BY-NC-ND 4.0), which permits the noncommercial replication and distribution of the article with the strict proviso that no changes or edits are made and the original work is properly cited (including links to both the formal publication through the relevant DOI and the license). See: https://creativecommons.org/licenses/by-nc-nd/4.0/.

\section{References}

1. Yamashita S, Tokuishi K, Anami K, et al. Thoracoscopic segmentectomy for T1 classification of non-small cell lung cancer: a single center experience. Eur J Cardiothorac Surg 2012;42:83-8.

2. Nagashima T, Shimizu K, Ohtaki Y, et al. An analysis of variations in the bronchovascular pattern of the right upper lobe using three-dimensional CT angiography and bronchography. Gen Thorac Cardiovasc Surg 2015;63:354-60.

3. Zhang M, Mao N, Wang SH, et al. The B1 defective type of bifurcated right upper lobe bronchus. J Thorac Dis 2019;11:4218-23.

4. Fourdrain A, De Dominicis F, Blanchard C, et al. Threedimensional CT angiography of anatomic variations in the pulmonary arterial tree. Surg Radiol Anat 2018;40:45-53.

5. Hiroaki Nomori, Morihito Okada. Illustrated Anatomical Segmentectomy for Lung Cancer. Springer (Tokyo), 2012.

6. Kandathil A, Chamarthy M. Pulmonary vascular anatomy \& anatomical variants. Cardiovasc Diagn Ther 2018;8:201-7.

(English Language Editor: B. Draper)

Cite this article as: Zhang $M$, Mao N, Zhang $\mathrm{K}$, Zhang M, Liu Y, Wang RF, Xiong T, Huang G, Shen JF, Liu J, Wu $\mathrm{QC}, \mathrm{Ge}$ MJ. Analysis of the variation pattern in left upper division veins and establishment of simplified vein models for anatomical segmentectomy. Ann Transl Med 2020;8(22):1515. doi: 10.21037/atm-20-6925 